\title{
PENGARUH MODEL COOPERATIF LEARNING TIPE JIGSAW TERHADAP HASIL BELAJAR MATA KULIAH PENANGANAN KEGAWATDARURATAN PADA MAHASISWA SEMESTER V
}

\author{
Ika Mardiyanti \\ Fakultas Keperawatan dan Kebidanan \\ Universitas Nahdlatul Ulama Surabaya Jl. Smea 57 Surabaya \\ Email: ika_mardiyanti@unusa.ac.id
}

\begin{abstract}
The learning model is one of the factors that influence student results. This study aims to determine the effect of cooperative learning model Jigsaw mode on the Result of Learning Emergency Management Course in Student Semester V at the University of NU Surabaya in 2015. The design of this research was Quasi Experimental cross sectional approach. The population in this study were all students throughout the class A fifth semester at the University of Nahdlatul Ulama Surabaya in 2015 amounted to 44 people. Samples were taken by sampling saturated, which in the 4 groups: the experimental group consisted of prior Jigsaw, after Jigsaw and the control group consisted of before the lecture, lecture sesuadah. The dependent variable in this study is the Learning Outcomes Management Training Courses Emergency Resuscitation On the newborn infant, and the independent variable is the type cooperative learning model Jigsaw. The research instrument used questionnaires, the data were analyzed by Friedman test with significance level $a=0.05$. Research shows that student results after using cooperative learning model Jigsaw mode almost half (33.3\%) get an A, while after using lecture learning model minority (23.8\%) of respondents received an A. From the analysis of Friedman Test level significance $\alpha=0.05, p$ $=0.000$ thus obtained $\mathrm{HO}$ rejected because $p<\alpha$ which means there Effect Model Jigsaw cooperative learning mode Learning Results Subjects of Emergency Handling of Newborn Resuscitation on Student Semester VNU At the University of Surabaya in 2015. in conclusion the learning model Jigsaw type of students more active, creative and better learning outcomes compared to conventional methods. With the use of appropriate learning models will be able to improve student results.
\end{abstract}

Keywords: learning model, the type of jigsaw, handling emergencies

ABSTRAK : Model pembelajaran merupakan salah satu faktor yang mempengaruhi hasil belajar mahasiswa. Penelitian ini bertujuan untuk mengetahui Pengaruh Model Cooperatif learning Tipe Jigsaw Terhadap Hasil Belajar Mata Kuliah Penanganan Kegawatdaruratan Pada Mahasiswa Semester V di Universitas Nahdlatul Ulama Surabaya Tahun 2015. Desain dalam penelitian ini adalah Quasi Eksperimental dengan pendekatan cross sectional. Populasi dalam penelitian ini adalah seluruh seluruh Mahasiswa kelas A semester V di Universitas Nahdlatul Ulama Surabaya tahun 2015 sebesar 44 orang. Sampel penelitian diambil secara sampling jenuh, yang di bagi 4 kelompok yaitu kelompok eksperimen terdiri dari sebelum Jigsaw, sesudah Jigsaw dan kelompok control terdiri dari sebelum ceramah, sesuadah ceramah. Variabel dependen dalam penelitian ini adalah Hasil Belajar Mata Kuliah Penanganan Kegawatdaruratan Tentang Resusitasi pada Bayi Baru Lahir, dan variabel independennya adalah Model Cooperatif learning Tipe Jigsaw. Instrumen penelitian menggunakan kuesioner, data dianalisis dengan Uji Friedman dengan tingkat kemaknaan $\alpha=0,05$. Hasil Penelitian menunjukkan bahwa hasil belajar mahasiswa setelah menggunakan Model Cooperatif Learning Tipe Jigsaw hampir setengahnya $(33,3 \%)$ 
mendapatkan nilai A, sedangkan setelah menggunakan Model pembelajaran ceramah sebagian kecil $(23,8 \%)$ responden mendapat nilai A. Dari analisis Friedmen Test tingkat kemaknaan $\alpha=0,05$ didapatkan $\mathrm{p}=0,000$ sehingga $\mathrm{H}_{0}$ ditolak karena $\mathrm{p}<\alpha$ yang berarti ada Pengaruh Model Cooperatif Learning Tipe Jigsaw Terhadap Hasil Belajar Mata Kuliah Penanganan Kegawatdaruratan tentang Resusitasi Bayi Baru Lahir Pada Mahasiswa Semester V Di Universitas Nahdlatul Ulama Surabaya Tahun 2015. Kesimpulannya dengan model pembelajaran tipe Jigsaw mahasiswa lebih aktif, kreatif dan hasil belajarnya lebih baik dibandingkan dengan metode konvensional. Dengan penggunaan model pembelajaran yang tepat maka akan dapat meningkatkan hasil belajar mahasiswa.

Kata kunci: model pembelajaran, tipe jigsaw, penanganan kegawatdaruratan

\section{PENDAHULUAN}

Model pembelajaran merupakan salah satu faktor yang mempengaruhi hasil belajar mahasiswa. Dalam pembelajaran dibutuhkan adanya perangkat pembelajaran yang memadai, seperti adanya dosen yang profesional, media dan alat pembelajaran yang memadai, kelas yang kondusif, dan serta model pembelajaran yang kooperatif (Ridwan, 2008). Dosen harus menciptakan suasana pembelajaran yang aktif, kreatif, kondusif, dan komunikatif (Hamalik, 2006). Di lapangan sering dijumpai pengajar yang dapat menguasai materi belajar dengan baik tetapi tidak dapat melaksanakan kegiatan pembelajaran dengan baik.

Ketika proses pembelajaran berlangsung, dosen dihadapkan pada berbagai masalah sehingga mahasiswa tidak dapat mengikuti dan memahami materi yang sedang dipelajari. Kesulitan tersebut antara lain dosen tidak dapat menciptakan suasana belajar menjadi aktif, yang pada akhirnya berakibat pada hasil belajar yang rendah. Padahal keterlibatan mahasiswa secara aktif mendorong untuk lebih mengerti dan memahami pelajaran. (Vasa, 2008)

\begin{tabular}{l}
\multicolumn{1}{c}{ Secara bertahap kurikulum } \\
mengalami penyempurnaan yang \\
bertujuan untuk meningkatkan mutu \\
pendidikan yang berorientasi pada \\
kemajuan sistem pendidikan nasional. \\
Namun demikian penyempurnaan
\end{tabular}

kurikulum tersebut tidak diimbangi dengan pelaksanaan kurikulum di dalam perkuliahan yang berupa proses pembelajaran. Berdasarkan pengamatan, proses pembelajaran di Prodi D-III Kebidanan Universitas NU Surabaya masih banyak dosen yang menggunakan model pembelajaran konvensional dengan metode ceramah dimana dosen sebagai pusat informasi menerangkan materi dan mahasiswa duduk manis mendengarkan dan mencatat materi yang disampaikan oleh dosen, sehingga mahasiswa menjadi pasif dan tidak kreatif, karena tidak ada kesempatan bertanya, berdiskusi baik dengan dosen maupun sesama mahasiswa. Dengan demikian motivasi untuk belajar kurang yang menyebabkan prestasi belajarnya rendah, hal ini terbukti dari banyaknya mahasiswa yang remidi pada akhir evaluasi pembelajaran.

Untuk menjadi seorang bidan, mahasiswa dituntut untuk menguasai mata kuliah salah satunya yang menunjang profesi kebidanan yaitu Penanganan Kegawatdaruratan, namun pada kenyataannya hasil belajar mata kuliah tersebut tergolong rendah. Berdasarkan data yang diperoleh di Universitas Nahdlatul Ulama Surabaya, Hasil Belajar Mata Kuliah Penanganan Kegawatdaruratan hampir setengahnya 43,47 \% mendapatkan nilai D dan sebagian kecil 2,08\% mendapat nilai A. Sehingga mahasiswa banyak yang mengulang dan menunjukkan rendahnya 
hasil belajar mata kuliah penanganan kegawatdaruratan.

Imbas atau dampak negatif yang dialami mahasiswa adalah hasil belajar menurun, motivasi belajar juga berkurang. Berdasarkan uraian permasalahan diatas perlu adanya perbaikan yang harus dilakukan oleh dosen. Rendahnya hasil belajar pada mahasiswa mencerminkan proses pendidikan dan pembelajaran yang gagal. Tentunya sebagai akibat rendahnya hasil belajar maka kualitas sumber daya manusia (SDM) juga terpengaruh. Jika belajar dilakukan secara aktif maka mahasiswa akan terdorong untuk mencari sesuatu,mencari jawaban atas pertanyaan, aktif memecahkan masalah dan menentukan penyelesaiannya. Menurut (Ahmadi, 2014) di antara penyebab mahasiswa rendah tingkat keaktifan dan hasil belajarnya, meliputi faktor internal dan eksternal. Faktor-faktor yang mempengaruhi hasil belajar adalah : faktor internal yang terdiri dari faktor jasmani, faktor psikologis, faktor kematangan fisik sedangkan faktor eksternal yang terdiri dari faktor sosial, faktor budaya, faktor lingkungan fisik. Di dalam faktor sosial terdapat lingkungan sekolah yang di dalamnya terdapat model pembelajaran.

Untuk meningkatkan prestasi belajar mahasiswa salah satunya diperlukan dosen yang kreatif dalam merencanakan model pembelajaran agar mahasiswa menjadi aktif dan inovatif yang pada akhirnya adalah suatu pemahaman mahasiswa terhadap materi yang dipelajarinya (Sobry, 2007). Menurut Gage dan Berliner dalam Sudrajat (2008) bahwa seorang dosen sebagai perancang, pengelola, penilai hasil pembelajaran, pengarah dan pembimbing mahasiswa. Proses pembelajaran akan berhasil dengan baik jika mengikutsertakan mahasiswa untuk memilih, menyusun dan ikut terjun pada situasi pembelajaran. Dengan melibatkan mahasiswa dalam pembelajaran mereka akan bertanggung jawab untuk melakukan rencana yang telah mereka susun (Lindy, 2004).

Model pembelajaran kooperatif merupakan hal yang sangat penting dalam menunjang interaksi antara mahasiswa dengan dosen. Kondisi seperti inilah yang sangat diharapkan agar interaksi berjalan dengan baik demi kelancaran pembelajaran. Model pembelajaran tipe Jigsaw merupakan salah satu model pembelajaran kooperatif, mahasiswa belajar dalam kelompok kecil yang terdiri dari 4-5 orang dengan memperhatikan keheterogenan, bekerjasama positif dan setiap anggota bertanggungjawab untuk mempelajari masalah tertentu dari materi yang diberikan dan menyampaikan materi tersebut kepada anggota kelompok yang lain (Vasa, 2008). Keunggulan kooperatif Jigsaw meningkatkan rasa tanggungjawab mahasiswa terhadap pembelajarannya sendiri dan juga pembelajaran orang lain, mahasiswa tidak hanya mempelajari materi yang diberikan, tetapi juga harus memberikan dan mengajarkan materi tertsebut kepada orang lain yaitu anggota kelompoknya yang lain.

\section{METODE}

Desain penelitian yang digunakan adalah penelitian Quasi Eksperimental dengan pendekatan cross sectional.

Populasi adalah seluruh Mahasiswa kelas A semester V di Universitas Nahdlatul Ulama Surabaya tahun 2015 sebesar 44 orang. Sampel penelitian diambil secara sampling jenuh, dimana semua anggota populasi digunakan sebagai sampel di bagi 4 kelompok yaitu kelompok eksperimen terdiri dari sebelum Jigsaw, sesudah Jigsaw dan kelompok control terdiri dari sebelum ceramah, sesuadah ceramah.

Variabel dependen dalam penelitian ini adalah Hasil Belajar Mata Kuliah 
Penanganan Kegawatdaruratan Tentang Resusitasi pada Bayi baru lahir, dan variabel independennya adalah Model Cooperatif learning Tipe Jigsaw.

Instrumen penelitian menggunakan kuesioner, data dianalisis dengan Uji Friedman dengan tingkat kemaknaan $\alpha=$ 0,05 .

\section{HASIL DAN PEMBAHASAN}

a. Hasil Penelitian

1. Data Umum

Karateristik Responden berdasarkan Minat pada kelompok Model Cooperatif Learning Tipe Jigsaw

Tabel 1 Distribusi Frekuensi Responden berdasarkan Minat pada kelompok Model Cooperatif Learning Tipe Jigsaw di UNUSA tahun 2015

\begin{tabular}{ccc}
\hline Minat & $\begin{array}{c}\text { Frekuensi } \\
(\mathrm{n})\end{array}$ & $\begin{array}{c}\text { Persentase } \\
(\%)\end{array}$ \\
\hline IPA & 18 & 85,7 \\
IPS & 3 & 14,3 \\
Lain-lain & 0 & 14,3 \\
\hline Jumlah & 21 & 100 \\
\hline
\end{tabular}

Sumber : Data primer, 2015

Pada tabel 1 menunjukkan bahwa hampir seluruhnya $(85,7 \%)$ responden minat IPA.

Karateristik Responden berdasarkan Minat pada kelompok Ceramah

Tabel 2 Distribusi Frekuensi Responden berdasarkan Minat pada kelompok Ceramah di UNUSA tahun 2015

\begin{tabular}{ccc}
\hline Minat & $\begin{array}{c}\text { Frekuensi } \\
(\mathrm{n})\end{array}$ & $\begin{array}{c}\text { Persentase } \\
(\%)\end{array}$ \\
\hline IPA & 16 & 76,2 \\
IPS & 5 & 23,8 \\
\hline Lain-lain & 0 & 0 \\
\hline
\end{tabular}

Sumber : Data primer, 2015
Pada tabel 2 dapat dilihat bahwa hampir seluruhnya $(76,2 \%)$ responden minat IPA.

Karakteristik responden berdasarkan kesiapan belajar pada kelompok Model Cooperatif Learning Tipe Jigsaw

Tabel 3 Distribusi frekuensi berdasarkan kesiapan belajar pada kelompok Model Cooperatif Learning Tipe Jigsaw di UNUSA tahun 2015

\begin{tabular}{lcc}
$\begin{array}{c}\text { Kesiapan } \\
\text { Belajar }\end{array}$ & $\begin{array}{c}\text { Frekuensi } \\
(\mathrm{n})\end{array}$ & $\begin{array}{c}\text { Persentase } \\
(\%)\end{array}$ \\
\hline Ya & 9 & 42,9 \\
Tidak & 12 & 57,1 \\
\hline Jumlah & 21 & 100 \\
\hline
\end{tabular}

Sumber : Data primer, 2015

Pada tabel 3 dapat dilihat bahwa sebagian besar $(57,1 \%)$ responden belum siap belajar.

Karakteristik Responden Berdasarkan Kesiapan Belajar pada Kelompok Ceramah

Tabel 4 Distribusi Frekuensi Responden Berdasarkan Kesiapan Belajar pada Kelompok Ceramah di UNUSA tahun 2015

\begin{tabular}{lcc}
$\begin{array}{c}\text { Kesiapan } \\
\text { Belajar }\end{array}$ & $\begin{array}{c}\text { Frekuensi } \\
(\mathrm{n})\end{array}$ & $\begin{array}{c}\text { Persentase } \\
(\%)\end{array}$ \\
\hline Ya & 8 & 38,1 \\
Tidak & 13 & 61,9 \\
\hline Jumlah & 21 & 100 \\
\hline
\end{tabular}

Sumber : Data primer, 2015

Pada tabel 4 dapat dilihat bahwa sebagian besar $(61,9 \%)$ responden tidak siap belajar.

Karakteristik Responden berdasarkan status sosial ekonomi keluarga pada kelompok Model Cooperatif Learning Tipe Jigsaw 
Tabel 5 Distribusi Frekuensi Reponden Berdasarkan status sosial ekonomi keluarga pada kelompok Model Cooperatif Learning Tipe Jigsaw di UNUSA tahun 2015

\begin{tabular}{lcc}
\hline \multicolumn{1}{c}{$\begin{array}{c}\text { Sosial } \\
\text { Ekonomi }\end{array}$} & $\begin{array}{c}\text { Frekuensi } \\
\text { Keluarga }\end{array}$ & $\begin{array}{c}\text { Persentase } \\
(\%)\end{array}$ \\
\hline Kelas Atas & 14 & 66,7 \\
Kelas & 5 & 23,8 \\
Menengah & & \\
Kelas & 2 & 9,5 \\
Bawah & & 100 \\
\hline \multicolumn{1}{c}{ Jumlah } & 21 & 100 \\
\hline
\end{tabular}

Sumber : Data primer, 2015

Pada tabel 5 menunjukkan bahwa sebagian besar $(66,7 \%)$ responden status ekonomi keluarganya kelas atas.

Karakteristik Responden berdasarkan status sosial ekonomi keluarga pada kelompok model pembelajaran ceramah

Tabel 6 Distribusi Frekuensi Reponden Berdasarkan status sosial ekonomi keluarga pada kelompok model pembelajaran ceramah di UNUSA tahun 2015

\begin{tabular}{lcc}
\hline \multicolumn{1}{c}{$\begin{array}{c}\text { Sosial } \\
\text { Ekonomi } \\
\text { Keluarga }\end{array}$} & $\begin{array}{c}\text { Frekuensi } \\
(\mathrm{n})\end{array}$ & $\begin{array}{c}\text { Persentase } \\
(\%)\end{array}$ \\
\hline Kelas Atas & 15 & 71,4 \\
Kelas & 5 & 23,8 \\
Menengah & & \\
Kelas & 1 & 4,8 \\
Bawah & & \\
\hline \multicolumn{1}{c}{ Jumlah } & 21 & 100 \\
\hline
\end{tabular}

Sumber : Data primer, 2015

Pada tabel 6 menunjukkan bahwa hampir seluruhnya $(71,4 \%)$ responden status ekonomi keluarganya kelas atas.

\section{Data Khusus}

Hasil Belajar Mahasiswa Sebelum Model Cooperatif Learning Tipe Jigsaw

Tabel 7 Distribusi frekuensi berdasarkan Hasil Belajar Sebelum Model Cooperatif Learning Tipe Jigsaw di UNUSA tahun 2015

\begin{tabular}{lcc}
\hline Kategori & Frekuensi & Persentase (\%) \\
\hline A & 0 & 0 \\
AB & 0 & 0 \\
B & 0 & 0 \\
BC & 5 & 23,8 \\
C & 3 & 14,3 \\
D & 7 & 33,3 \\
E & 6 & 28,6 \\
\hline Jumlah & 21 & 100 \\
\hline
\end{tabular}

Sumber : Data primer, 2015

Berdasarkan tabel di atas dapat di lihat bahwa hampir setengahnya $(33,3 \%)$ responden mendapat nilai $\mathrm{D}$.

Hasil Belajar Mahasiswa Sesudah Model Cooperatif Learning Tipe Jigsaw

Tabel 8 Distribusi frekuensi berdasarkan Hasil Belajar Sesudah Model Cooperatif Learning Tipe Jigsaw di UNUSA tahun 2015

\begin{tabular}{lcc}
\hline Kategori & Frekuensi & Persentase (\%) \\
\hline A & 7 & 33,3 \\
AB & 6 & 28,6 \\
B & 2 & 9,5 \\
BC & 4 & 19,1 \\
C & 2 & 9,5 \\
D & 0 & 0 \\
E & 0 & 0 \\
\hline Jumlah & 21 & 100 \\
\hline
\end{tabular}

Sumber : Data primer, 2015

Berdasarkan tabel 8 dapat di lihat bahwa hampir setengahnya $(33,3 \%)$ responden mendapat nilai $\mathrm{AB}$. 
Hasil Belajar Mahasiswa Sebelum Model Pembelajaran Ceramah

Tabel 9 Distribusi frekuensi berdasarkan Hasil Belajar Sebelum Model Pembelajaran Ceramah di UNUSA tahun 2015

\begin{tabular}{lcc}
\hline Kategori & Frekuensi & Persentase $(\%)$ \\
\hline $\mathrm{A}$ & 0 & 0 \\
$\mathrm{AB}$ & 0 & 0 \\
$\mathrm{~B}$ & 0 & 0 \\
$\mathrm{BC}$ & 0 & 0 \\
$\mathrm{C}$ & 3 & 14,3 \\
$\mathrm{D}$ & 7 & 33,3 \\
$\mathrm{E}$ & 11 & 52,4 \\
\hline Jumlah & 21 & 100 \\
\hline
\end{tabular}

Sumber : Data primer, 2015

Berdasarkan tabel 9 dapat di lihat bahwa sebagian besar $(52,4 \%)$ responden mendapat nilai $\mathrm{E}$.

Hasil Belajar Mahasiswa Sesudah Model Pembelajaran Ceramah

Tabel 10 Distribusi frekuensi berdasarkan Hasil Belajar Sesudah Model Pembelajaran Ceramah di UNUSA tahun 2015

\begin{tabular}{lcc}
\hline Kategori & Frekuensi & Persentase (\%) \\
\hline A & 5 & 23,8 \\
AB & 4 & 19,0 \\
B & 3 & 14,4 \\
BC & 4 & 19,0 \\
C & 4 & 19,0 \\
D & 1 & 4,8 \\
E & 0 & 0 \\
\hline Jumlah & 21 & 100 \\
\hline
\end{tabular}

Sumber : Data primer, 2015

Berdasarkan tabel 10 dapat di lihat bahwa sebagian kecil $(23,8 \%)$ responden mendapat nilai A.

Tabulasi silang antara Hasil belajar sebelum dan sesudah dilakukan Model Cooperatif Learning Tipe Jigsaw di UNUSA tahun 2015.
Tabel 11 Tabulasi silang antara Hasil belajar sebelum dan sesudah dilakukan Model Cooperatif Learning Tipe Jigsaw di UNUSA tahun 2015

\begin{tabular}{|c|c|c|c|c|}
\hline \multirow[t]{3}{*}{$\begin{array}{l}\text { Hasil } \\
\text { Belajar }\end{array}$} & \multicolumn{4}{|c|}{$\begin{array}{l}\text { Model Cooperatif Learning } \\
\text { Tipe Jigsaw }\end{array}$} \\
\hline & \multicolumn{2}{|c|}{ Sebelum } & \multicolumn{2}{|c|}{ Sesudah } \\
\hline & $\sum$ & $\%$ & $\sum$ & $\%$ \\
\hline A & 0 & 0 & 7 & 33,3 \\
\hline $\mathrm{AB}$ & 0 & 0 & 6 & 28,6 \\
\hline $\mathrm{B}$ & 0 & 0 & 2 & 9,5 \\
\hline $\mathrm{BC}$ & 5 & 23,8 & 4 & 19,1 \\
\hline $\mathrm{C}$ & 3 & 14,3 & 2 & 9,5 \\
\hline $\mathrm{D}$ & 7 & 33,3 & 0 & 0 \\
\hline $\mathrm{E}$ & 6 & 28,6 & 0 & 0 \\
\hline Total & 21 & 100 & 21 & 100 \\
\hline 0,05 & \multicolumn{3}{|c|}{$\mathrm{P}$ value $: 0,000$} & $\alpha=$ \\
\hline
\end{tabular}

Sumber : Data primer, 2015

Berdasarkan tabel di atas, dapat di interpretasikan bahwa sesudah dilakukan Model Cooperatif Learning Tipe Jigsaw dari 7 orang responden yang mendapat nilai $\mathrm{B}, 2$ orang diantaranya mendapat nilai E saat sebelum mendapat Model Cooperatif Learning Tipe Jigsaw, 2 orang mendapat nilai $\mathrm{C}$ dan $\mathrm{D}$ dan 1 orang mendapat nilai $\mathrm{BC}$.

Tabel 12 Tabulasi silang antara Hasil belajar sebelum dan sesudah dilakukan Model Pembelajaran Ceramah di UNUSA tahun 2015

\begin{tabular}{ccccc}
\hline Hasil & \multicolumn{4}{c}{ Model Ceramah } \\
\cline { 2 - 5 } Belajar & \multicolumn{2}{c}{ Sebelum } & \multicolumn{2}{c}{ Sesudah } \\
\cline { 2 - 5 } & $\sum$ & $\%$ & $\sum$ & $\%$ \\
\hline A & 0 & 0 & 5 & 23,8 \\
AB & 0 & 0 & 4 & 19,0 \\
B & 0 & 0 & 3 & 14,4 \\
BC & 0 & 0 & 4 & 19,0 \\
C & 3 & 14,3 & 4 & 19,0 \\
D & 7 & 33,3 & 1 & 4,8 \\
E & 11 & 52,4 & 0 & 0 \\
\hline
\end{tabular}




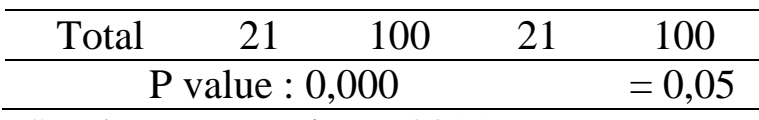

Sumber : Data primer, 2015

Berdasarkan tabel di atas, dapat dilihat bahwa sesudah dilakukan pembelajaran ceramah dari 5 orang responden yang mendapat nilai $\mathrm{A}, 3$ orang diantaranya mendapat nilai $\mathrm{C}$ saat sebelum mendapat Model pembelajaran ceramah sedangkan sisanya mendapat nilai D.

Dari hasil uji statistik dengan menggunakan Friedmen Test dengan bantuan SPSS (komputer) dengan tingkat kemaknaan $\alpha=0,05$ didapatkan $\mathrm{p}=0,000$ sehingga $\mathrm{H}_{0}$ ditolak karena $\mathrm{p}<\alpha$ yang berarti ada Pengaruh Model Cooperatif Learning Tipe Jigsaw Terhadap Hasil Belajar Mata Kuliah Penanganan Kegawatdaruratan Tentang Resusitasi Bayi Baru Lahir Pada Mahasiswa Semester V Di Universitas Nahdlatul Ulama Surabaya Tahun 2015.

\section{b. Pembahasan}

1. Hasil Belajar Mahasiswa Sebelum di lakukan Model Cooperatif Learning Tipe Jigsaw.

Model pembelajaran adalah suatu model yang dipilih dosen dalam proses pembelajaran yang dapat memberikan kemudahan atau fasilitas kepada mahasiswa menuju tercapainya tujuan yang telah ditetapkan. Dalam melaksanakan pembelajaran dosen harus mampu menggunakan model pembelajaran yang tepat agar tujuan pembelajaran dapat tercapai. Penelitian ini mempelajari sejauh mana model pembelajaran mempengaruhi peningkatan hasil belajar mahasiswa, dalam hal ini model yang digunakan adalah model pembelajaran Jigsaw. (Wahib, 2009)

Model pembelajaran Jigsaw merupakan model pembelajaran dimana mahasiswa diharapkan dapat bertanggungjawab atas penguasaan bagian materi belajar dan mampu mengajarakan materi tersebut kepada orang lain dalam kelompoknya. Dalam pembelajaran ini mahasiswa dituntut untuk berpikir secara kreatif dan bekerjasama dengan mahasiswa lain.. Dalam pembelajaran ini mahasiswa juga harus mampu membahas dan mempertanggungjawabkan apa yang dikerjakannya.

Konsep dalam model pembelajaran ini adalah diharapkan mahasiswa belajar dalam kelompok kecil yang terdiri dari 46 orang secara heterogen dan bekerja sama saling ketergantungan yang positif dan bertanggung jawab atas ketuntasan bagian materi pelajaran yang harus dipelajari dan menyampaikan materi tersebut kepada anggota kelompok orang lain. Jigsaw di desain untuk meningkatkan rasa tanggung jawab mahasiswa terhadap pembelajarannya sendiri dan juga pembelajaran orang lain. Mahasiswa tidak hanya mempelajari materi yang diberikan, tetapi mereka juga harus siap memberikan dan mengajarkan materi tersebut pada anggota kelompok yang lain. Dengan demikian, "Mahasiswa saling tergantung satu dengan yang lain dan harus bekerja sama secara kooperatif untuk mempelajari materi yang ditugaskan". (Lie, 2007)

Berdasarkan tabel 7 menunjukan bahwa hampir setengahnya $(33,3 \%)$ mahasiswa mendapat nilai $D$. Hal ini menunjukkan hasil belajar d bawah ratarata. Hasil Belajar mahasiswa dipengaruhi oleh beberapa faktor, salah satunya adalah kesiapan belajar. Menurut Sudjana (2010) kesiapan adalah keseluruhan kondisi sseorang yang membuatnya siap untuk memberi respon/jawaban di dalam cara tertentu terhadap suatu situasi. Penyesuaian kondisi pada suatu akan berpengaruh atau kecenderungan untuk memberi respon. Wahidmurni (2010) menjelaskan bahwa sesorang dapat dikatakan telah berhasil dalam belajar jika ia mampu menunjukkan adanya perubahan 
dalam dirinya. Perubahan-perubahan tersebut di antaranya dari segi kemampuan berpikirnya, keterampilannya, atau sikapnya terhadap suatu objek.

2. Hasil Belajar Mahasiswa Sesudah Model Cooperatif Learning Tipe Jigsaw

Berdasarkan tabel 8 menunjukkan bahwa hampir setengahnya $(33,3 \%)$ responden mendapat nilai A. Hal ini menunjukkan peningkatan nilai dari sebelum diajarkan. Pembelajaran kooperatif tipe Jigsaw adalah suatu tipe pembelajaran kooperatif yang terdiri dari beberapa anggota dalam satu kelompok yang bertanggung jawab atas penguasaan bagian materi belajar dan mampu mengajarkan materi tersebut kepada orang lain dalam kelompoknya. (Trianto, 2010). Dalam tehnik ini, mahasiswa dapat bekerja sama dengan mahasiswa lainnya dan mempunyai tanggung jawab lebih dan mempunyai banyak kesempatan pula untuk mengolah informasi yang di dapat dan meningkatkan keterampilan berkomunikasi dan bersosialisasi.

Model pembelajaran seperti ini harus dioptimalkan karena dapat meningkatkan kemampuan berkreatif mahasiswa dan tentunya meningkatkan prestasi mahasiswa. Di samping itu, pembelajaran ini juga dapat meningkatkan komunikasi mahasiswa karena berani menyampaikan apa yang telah ia dapat kepada kelompok lain maupun kelompok sendiri, sehingga mahasiswa yang kurang percaya diri untuk menyampaikan bisa dilatih untuk lebih berani dengan pembelajaran model ini. Disini, peran dosen adalah memfasilitasi dan memotivasi para anggota kelompok ahli agar mudah untuk memahami materi yang diberikan (Sobry, 2007).

Kunci tipe Jigsaw ini adalah kemandirian setiap mahasiswa terhadap anggota tim yang memberikan informasi yang diperlukan artinya para mahasiswa harus memiliki tanggunga jawab dan kerja sama yang positif dan saling ketergantungan untuk mendapatkan informasi dan memecahkan masalah yang diberikan. (Wahib, 2009)

Tabel 1 menunjukkan bahwa hampir seluruhnya $(85,7 \%)$ responden minat IPA. Menurut Wina (2010) mengatakan bahwa minat adalah suatu perpaduan keinginan dan kemauan yang dapat berkembang jika ada motivasi. Minat sangat besar pengaruhnya dalam mencapai dalam prestasi. Salah satu faktor yang mempengaruhi hasil belajar adalah minat. Minat dapat timbul dari ada daya tarik dari luar dengan juga datang dari hati sanubari. Jika minat IPA lebih banyak dari pada IPS maka pengetahuan tentang Penanganan Kegawatdaruratan mengenai Resusitasi Bayi Baru Lahir pun semakin baik.

\section{Hasil Belajar Sebelum Model Pembelajaran Ceramah \\ Berdasarkan tabel 9 menunjukkan} bahwa sebagian besar $(52,4 \%)$ responden mendapat nilai E. Ini menunjukkan buruknya hasil belajar, hasil belajar merupakan tujuan akhir dilaksanakannya kegiatan pembelajaran. Hasil belajar dapat ditingkatkan melalui usaha sadar yang dilakukan secara sistematis. Rendahnya hasil belajar mahasiswa merupakan salah satu masalah dalam pembelajaran. Sudjana (2010) mengemukakan adanya tiga faktor utama yang mempengaruhi hasil belajar, yaitu kemampuan kognitif, motivasi berprestasi dan kualitas pembelajaran. Kualitas pembelajaran adalah kualitas kegiatan pembelajaran yang dilakukan dan ini menyangkut model pembelajaran yang digunakan.

Model pembelajaran merupakan faktor eksternal yang mempengaruhi hasil belajar mahasiswa. Namun dalam proses belajar mengajar banyak hambatan yang sering muncul baik yang datang dari mahasiswa maupun dari dosen itu sendiri yang mencakup model pembelajaran yang diterapkan. Model pembelajaran yang digunakan pendidik memang bisa menjadi konduktor yang ampuh untuk menghantarkan materi pembelajaran. Di lapangan sering dijumpai pengajar yang 
dapat menguasai materi belajar dengan baik tetapi tidak dapat melaksanakan kegiatan pembelajaran dengan baik. Hal ini bisa jadi karena kegiatan belajar tersebut tidak didasarkan pada model pembelajaran yang sesuai sehingga hasil belajar yang diperoleh mahasiswa pun rendah.

\section{Hasil Belajar Sesudah Model Pembelajaran Ceramah \\ Berdasarkan tabel 10 menunjukkan} bahwa sebagian kecil $(23,8 \%)$ responden mendapat nilai A. Model Pembelajaran ceramah yang di anggap sebagai penyebab rendahnya minat belajar mahasiswa. Dalam Model pembelajaran Ceramah merupakan sebuah cara pengajaran yang dilakukan oleh dosen secara monolog dan hubungan satu arah. Menurut Trianto (2010) ceramah adalah penerangan dan penuturan secara lisan oleh guru terhadap kelasnya. Bagaimanakah seorang dosen mengorganisasikan kegiatan verbalnya itu dengan sebaik-baiknya agar menolong peserta didiknya belajar, salah satu cara yang dapat dipergunakan dosen adalah ceramah. Suasana belajar mengajar tidak efektif apabila pola komunikasi yang terjadi hanya satu arah, yakni dari dosen kepada mahasiswa. Untuk meningkatkan keefektifan pengajaran dengan metode ceramah, maka di samping memanfaatkan keunggulannya, juga diupayakan mengatasi kelemahannya.

Pada tabel 6 menunjukkan bahwa hampir seluruhnya $(71,4 \%)$ responden status ekonomi keluarganya kelas atas. Menurut Wahidmurni (2010), studi tentang manusia "sebagaimana mereka hidup dan berbuat serta berfikir dalam urusan kehidupan biasa". Keadaan ekonomi orang tua erat hubungannya dengan kesempatan anak untuk menikmati pendidikan. Dalam melaksanakan pendidikan diperlukan berbagai sarana dan prasarana serta biaya yang cukup. Orang yang mempunyai penghasilan yang tinggi atau keadaan ekonominya baik, tidak akan sulit dalam memenuhi kebutuhan sehari-hari . Dengan tingkat ekonomi yang demikian, mereka mempunyai kesempatan yang lebih banyak untuk memberikan kebutuhan anaknya dalam proses belajar yang sedang dijalaninya. Dengan terpenuhinya kebutuhan itu, akan menumbuhkan semangat anak untuk belajar. Hal ini memungkinkan anak akan memperoleh prestasi yang lebih baik. Lain halnya dengan mahasiswa yang berasal dari orang tua yang penghasilannya lemah atau tingkat ekonominya kurang baik, mereka akan memusatkan perhatiannya pada kebutuhan sehari-hari dari penghasilannya yang diterimanya. Keadaan yang demikian akan menjadikan hambatan bagi mahasiswa dalam mencapai prestasi belajar, karena konsentrasi belajar mereka terhambat oleh beberapa hal yang dihadapi.

5. Pengaruh Cooperatif Learning Tipe Jigsaw Terhadap Hasil Belajar Mata Kuliah Penanganan Kegawatdaruratan tentang Resusitasi Bayi Baru Lahir

Berdasarkan tabel 11 dapat dilihat bahwa sesudah dilakukan Model Cooperatif Learning Tipe Jigsaw dari 7 orang responden yang mendapat nilai $\mathrm{A}, 2$ orang diantaranya mendapat nilai $\mathrm{E}$ saat sebelum mendapat Model Cooperatif Learning Tipe Jigsaw, 2 orang mendapat nilai $C$ dan $D$ dan 1 orang mendapat nilai BC. Sedangkan berdasarkan tabel 12 dapat dilihat sesudah dilakukan pembelajaran ceramah dari 5 orang responden yang mendapat nilai A, 3 orang diantaranya mendapat nilai $\mathrm{C}$ saat sebelum mendapat Model pembelajaran ceramah sedangkan sisanya mendapat nilai D.

Dari hasil uji statistik dengan menggunakan Friedmen Test dengan bantuan SPSS (komputer) dengan tingkat kemaknaan $\alpha=0,05$ didapatkan $\mathrm{p}=0,000$ sehingga $\mathrm{H}_{0}$ ditolak karena $\mathrm{p}<\alpha$ yang berarti ada Pengaruh Model Cooperatif Learning Tipe Jigsaw Terhadap Hasil Belajar Mata Kuliah Penanganan 
Kegawatdaruratan Tentang Resusitasi pada Bayi Baru Lahir Pada Mahasiswa Semester V Di Universitas Nahdlatul Ulama Surabaya Tahun 2015.

Hasil penelitian menunjukkan bahwa Model Cooperatif Learning Tipe Jigsaw lebih baik baik dari pada model ceramah. Hal ini disebabkan dalam Model Cooperatif Learning Tipe Jigsaw penelitian mengenai pembelajaran kooperatif tipe Jigsaw telah memperlihatkan bagaimana strategi ini bisa mengembangkan pencapaian yang di buat para peserta didik. Hal ini sesuai dengan yang di kemukakan Trianto (2010) bahwa mahasiswa tidak hanya mempelajari materi yang diberikan, tetapi mereka juga harus siap memberikan dan mengajarkan materi tersebut kepada kelompoknya, sehingga para mahasiswa di tuntut lebih aktif dan memiliki tanggung jawab serta kerja sama yang positif. Jadi dengan penggunaan model pembelajaran yang tepat maka akan dapat meningkatkan prestasi belajar mahasiswa.

\section{SIMPULAN}

Berdasarkan hasil penelitian tentang hubungan inisiasi menyusu dini dengan kejadian hipotermi dapat disimpulkan sebagai berikut :

1. Hasil belajar mahasiswa sebelum pembelajaran dengan menggunakan Model Cooperatif Learning Tipe Jigsaw hampir setengahnya $(33,3 \%)$ responden mendapatkan nilai $\mathrm{D}$.

2. Hasil belajar mahasiswa sesudah pembelajaran dengan dengan Model Cooperatif Learning Tipe Jigsaw hampir setengahnya (33,3\%) mendapatkan nilai A.

3. Hasil belajar mahasiswa sebelum pembelajaran dengan menggunakan Model pembelajaran ceramah sebagian besar $(52,4 \%)$ responden mendapat nilai E.

4. Hasil belajar mahasiswa sesudah pembelajaran dengan menggunakan Model pembelajaran ceramah sebagian kecil $(23,8 \%)$ responden mendapat nilai A.

5. Ada pengaruh Model Cooperatif Learning Tipe Jigsaw Terhadap Hasil Belajar Mata Kuliah Penanganan Kegawatdaruratan Tentang Resusitasi Bayi Baru Lahir Pada Mahasiswa Semester V Di Universitas Nahdlatul Ulama Surabaya Tahun 2015.

\subsection{Saran}

1. Bagi Institusi pendidikan

Merancang model pembelajaran yang menarik dan menyenangkan dengan menerapkan model pembelajaran Jigsaw sehingga dapat membantu mahasiswa untuk menguasai materi pelajaran dengan baik serta menumbuhkan semangat dan gairah belajar siswa melalui model pembelajaran Jigsaw.

2. Bagi Peneliti Selanjutnya

Banyak variable penelitian yang belum diungkap secara mendalam dalam penelitian ini, misalnya dalam hal pengukuran hasil belajar hanya mengukur aspek kognitif mahasiswa. Oleh karena itu disarankan untuk diadakan penelitian lebih lanjut yang bertujuan untuk meningkatkan aspek afektif dan psikomotor sehingga akan lebih lengkap dalam menilai kompetensi yang dimiliki oleh mahasiswa.

\section{DAFTAR PUSTAKA}

Ahmadi, Abu, dkk. 2014. Psikologi Belajar. Jakarta : PT. Rineke Cipta

Sudrajat, Akhmad. 2008. "Cooperative Learning-Teknik Jigsaw". http://akhmadsudrajat.wordpress.co m. Diakses 12 Desember 2015

Hamalik, Oemar. 2006. Proses Belajar Mengajar. Jakarta : PT Bumi Aksara

Lie, Anita. 2007. Cooperative Learning. Jakarta : Grasindo

Lindy, Petersen. 2004. Bagaimana Memotivasi Anak Belajar. Jakarta : Gramedia 
Ridwan. 2008. Kegiatan Belajar dan Prestasi. http: // ridwan 202. wordpress.com. Diakses 10 Desember 2015

Sobry, Sutikno, M. 2007. Peran Guru dalam Membangkitkan Motivasi Belajar Siswa. www.bruderfic.or.id. Diakses 9 Desember 2015.

Sudjana, Nana. 2010. Penilaian Hasil Proses Belajar Mengajar. (Cet. XV). Bandung: PT. Ramaja Rosdakarya

Trianto. 2010. Mendesain Model Pembelajaran Inovatif-Progesif. Jakarta : Kencana

Vasa, Doantara. 2008. Aktivitas dan Prestasi Belajar". http://ipotes.wordpress.com. Diakses 5 Desember 2015

Wahib. 2009. Cooperative LearningTeknik Jigsaw. http://www.wahib- dr.com.Diakses 20 Desember 2015

Wahidmurni, Alifin Mustikawan, dan Ali Ridho. 2010. Evaluasi Pembelajaran : Kompetensi dan Praktik. Yogyakarta : Nuha Letera

Wina, Sanjaya.2010. Strategi Pembelajar an Berorientasi Standar Proses Pendidikan, Edisi Pertama. Jakarta : Kencana Prenada Media Group 